$\sqrt{B}$

J. Bio-Sci. 29(1): 11-22, 2021 (June)

ISSN 1023-8654

http://www.banglajol.info/index.php/JBS/index

DOI: https://doi.org/10.3329/jbs.v29i0.54818

\title{
ANTIMICROBIAL AND ANTICANCER ACTIVITIES OF SOME PARTIALLY ACYLATED THYMIDINE DERIVATIVES
}

\author{
SC Tasneem ${ }^{1}$, J Ferdous ${ }^{1}$, MZH Bulbul'1, MMH Misbah¹, D Sujan², I Hasan ${ }^{3}$ and \\ SMA Kawsar ${ }^{1^{*}}$ \\ ${ }^{1}$ Laboratory of Carbohydrate and Nucleoside Chemistry, Department of Chemistry, Faculty of Science, \\ University of Chittagong, Bangladesh \\ 2Department of Microbiology, Faculty of Biological Science, University of Chittagong, Bangladesh \\ ${ }^{3}$ Department of Biochemistry and Molecular Biology, Faculty of Science, University of Rajshahi, Bangladesh
}

\begin{abstract}
The principal cause of human deaths in the world is primarily due to harmful pathogenic microbes as bacteria, a virus, and fungi. Searching for antimicrobial agents to prevent deaths with new structures and modes of action is an essential strategy of the research. Therefore, in the present study has been undertaken of thymidine and of its eleven acylated derivatives were employed as test chemicals for in vitro antibacterial evaluation against five human pathogenic bacteria. The compounds were also screened for antifungal functionality tests against two phytopathogenic fungi. It was observed that a good number of tested compounds exhibited moderate to good antimicrobial activities. It was also observed that these acylated compounds were more effective against the phytopathogenic fungi than those of the bacterial strains. Encouragingly, several tested chemicals showed better antibacterial and antifungal activities than the standard antibiotics employed. The minimum inhibition concentration (MIC) values of the compounds 3 (5'-O-butyrylthymidine), 7 (5'-0-palmitoylthymidine) and 12 (5'-0-4dichloroacetylthymidine) were found to be $0.32 \mathrm{mg} / \mathrm{ml}$ and minimum bactericidal concentrations (MBC) values were found to be $0.63 \mathrm{mg} / \mathrm{ml}$ in each case. On the other hand, the minimum fungal concentration (MFC) was found to be $(1.25 \mathrm{mg} / \mathrm{ml})$ in the case of compound 7 (i.e., palmitoyl derivative) which may be used as antifungal active drug providing further investigation. In vitro MTT assays revealed that compounds 4 (5'-O-hexanoylthymidine) and 7 (5'-O-palmitoylthymidine) were effective against Ehrlich's ascites carcinoma (EAC) cells and $\mathrm{IC}_{50}$ values were found to be $920.88 \mu \mathrm{g} / \mathrm{ml}$ and $792.90 \mu \mathrm{g} / \mathrm{ml}$, respectively. So these compounds may be targeted for future studies for their usage as broad-spectrum antibiotics.
\end{abstract}

Key words: Antibacterial, Antifungal, Anticancer, Pathogens, Thymidine

\section{Introduction}

Nucleotides and nucleosides are key compounds involved in major biological processes, such as nucleic acids and protein synthesis, cell signaling, enzyme regulation, and metabolism. Indeed, many nucleoside analogs are already clinically used as anticancer, antiviral and antitumoral agents (Clercq 2010 \& 2011, Tashiro et al. 2012). As antibacterial agents, some nucleoside derivatives have shown moderate to good activity against specific bacterial strains (Kimura et al. 2003). However, their efficiency is sometimes reduced by the appearance of resistance mechanisms (Najera 2013). The availability of new nucleoside derivatives (Jordheim et al. 2013), therefore, is still of prime importance.

*Author for correspondence: akawsarabe@yahoo.com 
Nucleoside and their derivatives have emerged as molecules with potentially useful therapeutic properties that have gained considerable attention from both synthetic and medicinal chemists due to their versatile biological activities in various therapeutic areas. Zidovudine (3'-azido-3'-deoxythymidine) is the first approved drug for the treatment of HIV (Yarchoan et al. 1988), marketed under the brand name Retrovir.

In the last few decades, considerable works have been done in the field of antimicrobial activity to studies of a wide variety of chemical compounds (Ghorab et al. 2004). It must, however, be admitted that a lot of the benefits of one or more chemicals were based on empirical knowledge. Different classes of chemicals have been screened all over the world. Nucleosides, especially acylated thymidine (Arifuzzan et al. 2018) and uridine (Kawsar et al. 2018, Sumi et al. 2019) are very important due to their effective biological activity (Parang et al. 1997, Johannes et al. 2010). A literature survey revealed that a large number of biologically active compounds possess aromatic, heteroaromatic and acyl substituents (Hui et al. 2002, Patel et al. 2002). Nitrogen, sulphur and halogen-containing substituents are also known to enhance the biological activity of the parent compound (Kawsar et al. 2014). It is also known that if an active nucleus is linked to another active nucleus, the resulting molecule may possess greater potential for biological activity (Gupta et al. 1997). The benzene and substituted benzene nuclei play an important role as a common denominator for various antimicrobial activities (Kabir et al. 2004).

It was also observed that substituted nucleoside derivatives containing aromatic, heteroaromatic and acyl substituents along with chlorine, bromine, sulphur enhances the biological activity many folds than the precursor compounds (Kabir et al. 2003, Kawsar et al. 2015a\&b, 2016). In this background, the present attempt has been undertaken to explore the antibacterial, antifungal and anticancer potential activities of some acylated derivatives of thymidine as the first time.

\section{Materials and Methods}

\section{Tested chemicals}

Some partially protected derivatives of thymidine (Table 1) were used as test chemicals. The chemicals were synthesized, isolated, purified and characterized in the lab of carbohydrate and nucleoside chemistry (LCNC), Department of Chemistry, University of Chittagong. The antimicrobial assays of the chemicals were done in the Molecular Microbiology Laboratory, Department of Microbiology, Chittagong University and the tested micro-organisms (bacteria and fungi) were collected from this Laboratory. In all the cases, dimethyl sulfoxide (DMSO) was used as a solvent for the test chemicals and a 1.05\% and $0.5 \%$ solution of the compound was used in the experiment. Proper control was maintained with DMSO without chemicals. Two standard antibiotics, azithromycin and nystatin were tested for comparison.

\section{Used bacteria}

The following Gram-positive and Gram-negative bacteria were used as test organisms for antibacterial evaluation of the test chemicals (1-12): Bacillus subtilis ATCC 6633, Staphylococcus aureus ATCC 6538, Escherichia coli ATCC 8739, Salmonella abony NCTC 6017 and Pseudomonas aeruginosa ATCC 9027.

\section{Used fungi}

The following fungal phytopathogens were used as test fungi:

Aspergillus niger ATCC 16404 and Candida albicans ATCC 10231. 


\section{Antibacterial activity test}

In vitro antibacterial activities of the synthesized thymidine derivatives (Table 1) were carried out by the disc diffusion method (Bauer et al. 1966). Mueller Hinton agar (MHA) media was distributed in sterilized Petri dishes. Bacterial suspension $(0.1 \mathrm{ml})$ was taken in the sterile Petri dish and about $15-20 \mathrm{ml}$ agar media was poured. Then it was rotated clock and anti-clockwise and waited for solidification. The paper discs $(5 \mathrm{~mm}$ in diameter) have been soaked $(20 \mu / / d i s c)$ with leaf extracts for antibacterial analysis. In performing the sensitivity spectrum analysis agar medium plate haa been selected uniformly with the test organisms. Then the discs prepared with definite solvent extract have been placed on the medium surface. On the other hand, a disc containing each solvent was used as control (C). These plates are then kept at low temperature $\left(4^{\circ} \mathrm{C}\right)$ for two to four hours to allow maximum diffusion of the compound. During this time dried discs absorb water from the surrounding media and then the test materials are dissolved and diffused out of the media. The diffusion occurs according to the physical law that controls the diffusion of molecules through agar gel. The plates were then incubated at $37{ }^{\circ} \mathrm{C}$ for $24 \mathrm{~h}$ at the inverted position to allow maximum growth of the microorganisms. After incubation, the plates have been observed and results were noted as the "Zone of Inhibition" (clear distinct zone around the discs) in $\mathrm{mm}$ in diameter with a transparent scale including the diameter of the discs. The diameter of the zone of inhibition was observed and measured in $\mathrm{mm}$ by a transparent scale. Each experiment was repeated thrice. The standard antibiotic Azithromycin (BEXIMCO Pharm. Ltd., Bangladesh) was used as a positive control and compared with tested chemicals under identical conditions.

\section{The minimum inhibitory concentration (MIC) and minimum bactericidal concentrations (MBC)}

The MIC and MBC of the compounds that showed activity against the aforementioned organisms were determined by applying different concentrations of the compounds alongside the same bacterial loads in a nutrient broth. MIC and MBC were determined via the broth microdilution method (Amsterdam 2005).

\section{Antifungal activity studies}

The in vitro antifungal activities of the synthesized thymidine derivatives (Table 1) were investigated against two plant pathogenic fungi. The "poisoned food" technique (Grover and Moore 1962) was used to screen for antifungal activity in which potato dextrose agar (PDA) was used as the culture medium. The test compounds were dissolved in dimethyl sulfoxide (DMSO) to a $1 \%(\mathrm{w} / \mathrm{v})$ concentration. From this, a sterilized pipette was used to transfer $0.1 \mathrm{ml}$ (containing $1 \mathrm{mg}$ of the respective compound being tested) to a sterile petri dish, after which $20 \mathrm{ml}$ of the medium was poured into the petri dish and allowed to solidify. Inoculation was performed at the center of each petri dish with a $5 \mathrm{~mm}$ mycelium block of each fungus. The mycelium block was prepared by applying a corkscrew to the growing area of a 5-day-old culture of the test fungi on PDA. The blocks were placed at the center of each petri dish in an inverted position to maximize contact between the mycelium and the culture medium. The inoculation plates were incubated at $25^{\circ} \mathrm{C} \pm 2^{\circ} \mathrm{C}$, and the experiment was conducted in triplicate. A control sample (i.e., PDA without any test chemicals applied) was also maintained under the same conditions. After 5 days of incubation, the diameter of the fungal radial mycelia growth was measured. The average of three measurements was taken as the radial mycelia growth of the fungus in $\mathrm{mm}$. The percentage inhibition of mycelial growth of the test fungus was calculated as follows:

$$
I=\left\{\frac{\mathrm{C}-\mathrm{T}}{\mathrm{C}}\right\} \times 100
$$


Where, $\mathrm{I}=$ percentage of inhibition, $\mathrm{C}=$ diameter of the fungal colony in the control (DMSO), and $\mathrm{T}=$ diameter of the fungal colony during treatment. The results obtained were compared with those of the standard antifungal agent Nystatin.

\section{The minimum fungal concentration (MFC)}

MFC was also assessed by testing various concentrations of the derivatives against fungal cultures.

\section{Anticancer activity}

\section{MTT colorimetric assay}

In this study (Ahmed et al. 2017), adult Swiss albino mice were first obtained from the International Center for Diarrhoeal Disease Research, Bangladesh (ICDDR'B). Cells were harvested from the mice, and their viability was checked using the trypan blue exclusion assay. MTT (3-(4,5-dimethylthiazol-2-y))-2,5diphenyltetrazolium bromide) colorimetric assay was used to detect in vitro proliferation of EAC cells. Viable EAC cells ( $5 \times 10^{5}$ in $200 \mu \mathrm{l}$ RPMI-1640 media) were placed in a 96-well culture plate in the presence and absence of different concentrations of the respective derivative under investigation $(12.5-200 \mu \mathrm{g} / \mathrm{ml})$ and incubated at $37^{\circ} \mathrm{C}$ in a $\mathrm{CO}_{2}$ incubator for $24 \mathrm{~h}$. After removal of an aliquot from each well, $10 \mathrm{mM}$ of PBS $(180 \mu \mathrm{l})$ and MTT $\left(20 \mu \mathrm{l}, 5 \mathrm{mg} / \mathrm{ml} \mathrm{MTT}\right.$ in PBS) was added, and the plate was incubated at $37^{\circ} \mathrm{C}$ for $4 \mathrm{~h}$. Then, an aliquot was removed again, and $200 \mu \mathrm{l}$ of acidic isopropanol was added to each well. The plate was agitated for $5 \mathrm{~min}$ and incubated at $37^{\circ} \mathrm{C}$ for $1 \mathrm{~h}$ before absorbance values were measured at $570 \mathrm{~nm}$ using a titer plate reader. The cell proliferation inhibition ratio was calculated as follows:

Proliferation inhibition ratio $(\%)=\{(A-B) \times 100\} / A$,

Where, $A=O D_{570} \mathrm{~nm}$ of the cellular homogenate (control) without the derivative and

$\mathrm{B}=\mathrm{OD} 570 \mathrm{~nm}$ of the cellular homogenate with the derivative added.

\section{Results and Discussion}

\section{Effects of test chemicals against bacteria}

The results of the antibacterial activity of the test compounds (Table 1) were measured in terms of zone of inhibition and are presented in Table 2, Table 3 and Fig. 1. The compounds showed a promising inhibitory activity against a number of both Gram-positive and Gram-negative bacteria. The inhibition data (Table 2) indicated that compound 7 exhibited more active $(19.0 \pm 0.11 \mathrm{~mm})$ against Staphylococcus aureus which is very close to the standard antibiotic azithromycin $(20.0 \pm 0.19 \mathrm{~mm})$. However, compounds 2,4 and 12 were also excellent active on the same organism and showed $(16.0 \pm 0.11 \mathrm{~mm}),(15.0 \pm 0.14 \mathrm{~mm})$ and $(17.0 \pm$ $0.13 \mathrm{~mm}$ ) diameter of inhibition zone, respectively. In addition, compound 12 showed the highest inhibition zone $(16.0 \pm 0.17 \mathrm{~mm})$ against Bacillus subtilis. On the other hand (Table 3), compound 7 showed the highest inhibition zone $(17.0 \pm 0.29 \mathrm{~mm})$ against Escherichia coli. However, compounds $3(15.0 \pm 0.22 \mathrm{~mm})$, $4(16.0 \pm 0.25 \mathrm{~mm})$ both showed good activity against $E$. coli and 8 also exhibited good activity against $S$. abony $(16.0 \pm 0.18 \mathrm{~mm})$. The rest of the compounds also showed somewhat activity but they are of less significant compared to the tested compounds. Moreover, compounds 1, 9, 10 and 11 did not show any inhibition against the bacterial strains examined. From the results, it was also observed that most of the compounds were very effective against bacterial strains that led us to carry out the MIC and MBC tests for these compounds and the results are presented in Tables 4 and 5. 
Table 1. Name of the tested compounds

\begin{tabular}{ccc}
\hline Compound No. & Name of the tested compounds & Molecular formula \\
\hline 1 & Thymidine & $\mathrm{C}_{10} \mathrm{H}_{14} \mathrm{~N}_{2} \mathrm{O}_{5}$ \\
2 & $5^{\prime}$-O-Propionylthymidine & $\mathrm{C}_{12} \mathrm{H}_{18} \mathrm{O}_{5} \mathrm{~N}_{2} \mathrm{CO}$ \\
3 & $5^{\prime}$-O-Butyrylthymidine & $\mathrm{C}_{13} \mathrm{H}_{20} \mathrm{O}_{5} \mathrm{~N}_{2} \mathrm{CO}$ \\
4 & $5^{\prime}$-O-Hexanoylthymidine & $\mathrm{C}_{15} \mathrm{H}_{24} \mathrm{O}_{5} \mathrm{~N}_{2} \mathrm{CO}$ \\
5 & $5^{\prime}$-O-Nonanoylthymidine & $\mathrm{C}_{19} \mathrm{H}_{30} \mathrm{O}_{6} \mathrm{~N}_{2}$ \\
6 & $5^{\prime}$-O-Lauroylthymidine & $\mathrm{C}_{21} \mathrm{H}_{26} \mathrm{O}_{5} \mathrm{~N}_{2} \mathrm{CO}$ \\
7 & $5^{\prime}$-O-Palmitoylthymidine & $\mathrm{C}_{19} \mathrm{H}_{33} \mathrm{O}_{5} \mathrm{~N}_{2} \mathrm{CO}$ \\
8 & $5^{\prime}$-O-stearoylthymidine & $\mathrm{C}_{27} \mathrm{H}_{48} \mathrm{O}_{5} \mathrm{~N}_{2} \mathrm{CO}$ \\
9 & $5^{\prime}-$ O-4-Chlorobenzoylthymidine & $\mathrm{C}_{16} \mathrm{H}_{17} \mathrm{O}_{5} \mathrm{~N}_{2} \mathrm{CO}$ \\
10 & $5^{\prime}$-O-3-Bromobenzoylthymidine & $\mathrm{BrC}_{16} \mathrm{H}_{17} \mathrm{O}_{5} \mathrm{~N}_{2} \mathrm{CO}$ \\
11 & 5'-O-Tritylthymidine & $\mathrm{C}_{29} \mathrm{H}_{28} \mathrm{O}_{5} \mathrm{~N}_{2}$ \\
12 & 5'-O-4-Dichloroacetylthymidine & $\mathrm{Cl}_{2} \mathrm{C}_{11} \mathrm{H}_{14} \mathrm{O}_{5} \mathrm{~N}_{2} \mathrm{CO}$ \\
\hline
\end{tabular}

Table 2. Zone of inhibition observed for Gram-positive bacteria

\begin{tabular}{|c|c|c|}
\hline \multirow[t]{2}{*}{ Compound No. } & \multicolumn{2}{|c|}{ Diameter of the zone of inhibition in mm $200 \mu \mathrm{g} \mathrm{dw}$./disc } \\
\hline & Bacillus subtilis & Staphylococcus aureus \\
\hline 1 & $\mathrm{NI}$ & $\mathrm{NI}$ \\
\hline 2 & $\mathrm{NI}$ & $\star 16.0 \pm 0.11$ \\
\hline 3 & $\star 14.0 \pm 0.20$ & $\mathrm{NI}$ \\
\hline 4 & $\mathrm{NI}$ & *15.0 0.14 \\
\hline 5 & $9.0 \pm 0.22$ & $10.0 \pm 0.16$ \\
\hline 6 & $11.0 \pm 0.30$ & $\mathrm{NI}$ \\
\hline 7 & $* 15.0 \pm 0.21$ & $* 19.0 \pm 0.11$ \\
\hline 8 & $7.0 \pm 0.32$ & $12.0 \pm 0.20$ \\
\hline 9 & $\mathrm{NI}$ & $\mathrm{NI}$ \\
\hline 10 & $\mathrm{NI}$ & $\mathrm{NI}$ \\
\hline 11 & $\mathrm{NI}$ & $\mathrm{NI}$ \\
\hline 12 & *16.0 00.17 & *17.0 0.13 \\
\hline \multicolumn{3}{|l|}{ Azithromycin } \\
\hline$(200 \mu \mathrm{g} \mathrm{dw} . / \mathrm{disc})$ & $\star \star 18.0 \pm 0.16$ & $\star * 20.0 \pm 0.19$ \\
\hline
\end{tabular}

$\mathrm{NI}=$ No inhibition. 
From the experimental results obtained by using a number of selected human pathogenic bacteria (as shown in Table 2, Table 3 and Fig. 1), we found that selectively acylated derivatives 2, 3, 7 and 12 showed moderate to marked inhibition against Gram-positive bacteria while chemicals 4, 6, 7 and 12 are very active against Gram-negative bacteria. We also observed that some compounds such as 3, 4, 7 and 8 are active against both the Gram-positive and Gram-negative organisms. So these compounds may be targeted for future studies for their usage as broad-spectrum antibiotics.

Table 3. Zone of inhibition observed for Gram-negative bacteria

\begin{tabular}{|c|c|c|c|}
\hline \multirow[t]{2}{*}{ Compound No. } & \multicolumn{3}{|c|}{ Diameter of the zone of inhibition in $\mathrm{mm} 200 \mu \mathrm{g} \mathrm{dw}$./disc } \\
\hline & Escherichia coli & Salmonella abony & Pseudomonas aeruginosa \\
\hline 1 & $\mathrm{NI}$ & $\mathrm{NI}$ & $\mathrm{NI}$ \\
\hline 2 & $\mathrm{NI}$ & $\mathrm{NI}$ & $9.0 \pm 0.28$ \\
\hline 3 & *15.0 \pm 0.22 & $\mathrm{NI}$ & $12.0 \pm 0.12$ \\
\hline 4 & *16.0 0.25 & $\mathrm{NI}$ & $\star 15.0 \pm 0.11$ \\
\hline 5 & $10.0 \pm 0.15$ & $\mathrm{NI}$ & *14.0 0.31 \\
\hline 6 & $12.0 \pm 0.11$ & $13.0 \pm 0.35$ & $\mathrm{NI}$ \\
\hline 7 & $\star 17.0 \pm 0.29$ & $* 15 \pm 0.30$ & $* 13 \pm 0.19$ \\
\hline 8 & $\star 13.0 \pm 0.18$ & $\star 16.0 \pm 0.18$ & $12.0 \pm 0.21$ \\
\hline 9 & $\mathrm{NI}$ & $\mathrm{NI}$ & $\mathrm{NI}$ \\
\hline 10 & $\mathrm{NI}$ & $\mathrm{NI}$ & $\mathrm{NI}$ \\
\hline 11 & $\mathrm{NI}$ & $\mathrm{NI}$ & $\mathrm{NI}$ \\
\hline 12 & *14.0 0.15 & $\mathrm{NI}$ & $\mathrm{NI}$ \\
\hline \multicolumn{4}{|l|}{ Azithromycin } \\
\hline$(200 \mu \mathrm{g} \mathrm{dw} . / \mathrm{disc})$ & $\star * 18 \pm 0.39$ & $\star * 19 \pm 0.38$ & $* * 19 \pm 0.39$ \\
\hline
\end{tabular}

$\mathrm{NI}=$ No inhibition. 
A

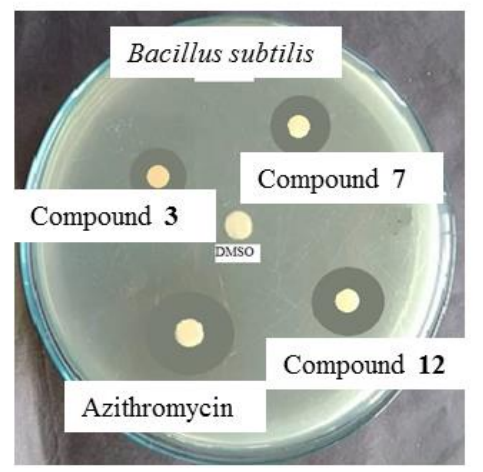

B

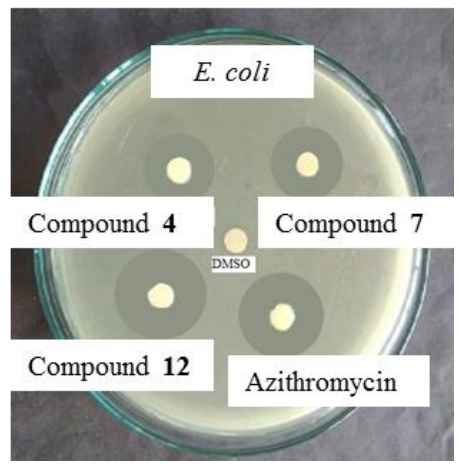

Fig. 1: Percentage of inhibition observed for A) B. subtilis by compounds 3,7 , and 12 ; B) $E$. coli by compounds 4, 7, and 12. DMSO was the negative control, whereas Azithromycin represented the positive control.

MIC and MBC methods are widely used in the comparative testing of new agents. The minimum inhibition concentration (MIC) is the minimum concentration of the antibacterial agent in a given culture medium below which bacterial growth is not inhibited. In clinical laboratories, they are used to establish the susceptibility of organisms that give equivocal results in disc tests, for tests on organisms where disc tests may be unreliable and when a more accurate result is required for clinical management. The MIC values (Table 4) of the compounds 3, 7 and 12 were found to be $0.3125 \mathrm{mg} / \mathrm{ml}$ in each case against Bacillus subtilis, Escherichia coli and Pseudomonas aeruginosa, respectively. The MIC is indicative of the usefulness of these compounds as antimicrobial drugs but some other experiments must be carried out before these can be used as effective drugs. In addition, the minimum bactericidal concentrations (MBC) values (Table 5) of the chemicals 3, 7 and 12 were found to be $0.625 \mathrm{mg} / \mathrm{ml}$ in each case.

Table 4. MIC of test chemicals against five bacteria

\begin{tabular}{cccccc}
\hline Compound No. & \multicolumn{5}{c}{ MIC values in mg/ml } \\
\cline { 2 - 6 } & $\begin{array}{c}\text { Bacillus } \\
\text { subtilis }\end{array}$ & $\begin{array}{c}\text { Staphylococcus } \\
\text { aureus }\end{array}$ & Escherichia coli & $\begin{array}{c}\text { Salmonella } \\
\text { abony }\end{array}$ & $\begin{array}{c}\text { Pseudomonas } \\
\text { aeruginosa }\end{array}$ \\
\hline 3 & 0.32 & $\mathrm{NF}$ & 0.63 & $\mathrm{NF}$ & 1.25 \\
7 & 0.63 & 1.25 & 0.32 & 0.63 & 0.63 \\
12 & 0.63 & 0.63 & 0.32 & 0.63 & 0.32 \\
\hline
\end{tabular}

NF = Not found. 
Table 5. MBC of test chemicals against five bacteria

\begin{tabular}{cccccc}
\hline Compound No. & \multicolumn{5}{c}{ MBC in mg/ml } \\
\cline { 2 - 6 } & B. subtilis & S. aureus & E. coli & S. abony & P.aeruginosa \\
\hline 3 & 0.63 & NF & 1.25 & NF & 2.50 \\
7 & 1.25 & 2.50 & 0.63 & 1.25 & 1.25 \\
12 & 1.25 & 1.25 & 0.63 & 1.25 & 0.63 \\
\hline
\end{tabular}

$\mathrm{NF}=$ Not found.

As the tested chemicals have shown remarkable inhibitory activity against three potential pathogenic bacteria i.e. Bacillus subtilis, Escherichia coli and Pseudomonas aeruginosa, the compounds should be subjected to further experiments to evaluate their efficacy. So, the above three compounds (i.e., 3, 7 and 12) can be used as therapeutic antibacterial agents against various infectious diseases caused by these test organisms after investigating their side effects and other necessary experiments.

\section{Effects of test chemicals against fungi}

The antifungal activity of the test compounds were tested against two phytopathogenic fungi and compared with that of antifungal antibiotic Nystatin. The results of the inhibition of fungal mycelial growth are given in Table 6 and Fig. 2. The tested compounds displayed marked toxicities towards a number of fungal phytopathogens. The antifungal screening data (Table 6) suggests that the test compound $7(67.0 \pm 0.80 \%)$ showed marked toxicities towards Aspergillus niger, even higher than the standard antibiotic, Nystatin (66.4 $\pm 0.43 \%)$; compounds $2(53.0 \pm 0.26 \%), 3(55.0 \pm 0.31 \%)$ and $12(60.34 \pm 0.29 \%)$ showed excellent inhibition against this same pathogen. On the other hand, compounds $2(60.0 \pm 0.32 \%), 3(56.0 \pm 0.36 \%), 7$ $(61.0 \pm 0.32 \%)$ and $12(62.0 \pm 0.22 \%)$ showed good inhibition against Candida albicans, being comparable to Nystatin $(63.1 \pm 0.37 \%)$.

Table 6. Antifungal activity by the test compounds

\begin{tabular}{ccc}
\hline Compound No. & \multicolumn{2}{c}{ \% Inhibition of fungal mycelial growth } \\
\cline { 2 - 3 } & Aspergillus niger & Candida albicans \\
\hline 1 & $\mathrm{NI}$ & $\mathrm{NI}$ \\
2 & $* 53.0 \pm 0.26$ & $* 60.0 \pm 0.32$ \\
3 & $* 55.0 \pm 0.31$ & $* 56.0 \pm 0.36$ \\
4 & $* 48.0 \pm 0.20$ & $* 48.0 \pm 0.41$ \\
5 & $15.10 \pm 0.29$ & $12.0 \pm 0.33$ \\
6 & $14.10 \pm 0.32$ & $24.0 \pm 0.31$ \\
7 & $* 67.0 \pm 0.80$ & $* 61.0 \pm 0.32$ \\
8 & $20.0 \pm 0.41$ & $\mathrm{NI}$ \\
9 & $\mathrm{NI}$ & $\mathrm{NI}$ \\
10 & $30.33 \pm 0.28$ & $\mathrm{NI}$ \\
11 & $25.21 \pm 0.33$ & $\mathrm{NI}$ \\
12 & $* 60.34 \pm 0.29$ & $* 62.0 \pm 0.22$ \\
Nystatin & $* * 66.4 \pm 0.43$ & $* 63.1 \pm 0.37$ \\
\hline
\end{tabular}

$\mathrm{NI}=$ No inhibition. 
C

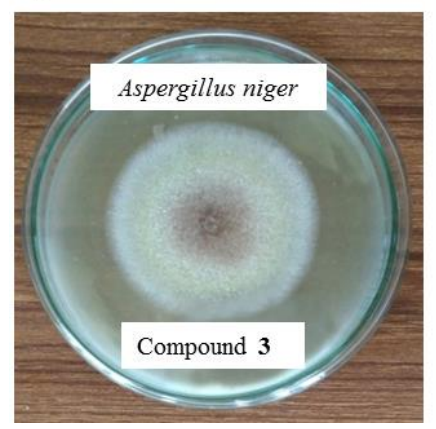

D

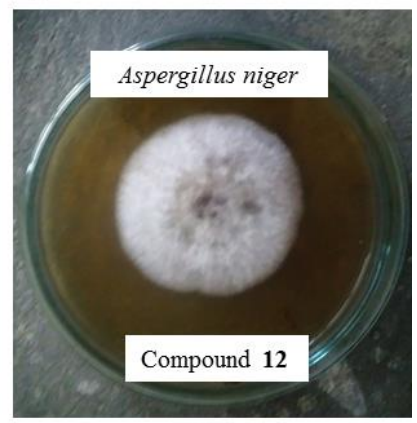

Fig. 2: Percentage zone of mycelial growth inhibition for compounds 3 and 12 against $A$. niger (C and $D$, respectively).

Compounds which had greater zones of inhibition, i.e., compounds 7 and 12 were subjected to further analyses (determination of MIC, and MFC) to test their activity against other commonly occurring microbes. These results are presented in Table 7. According to Table 7, compound 7 (palmitoyl derivative) exhibited higher MIC $(0.63 \mathrm{mg} / \mathrm{ml})$ and MFC $(1.25 \mathrm{mg} / \mathrm{ml})$ activity than the compound 12 (dichloroacetyle derivative) against Candida albicans. So, it can be inferred that compound 7 (i.e., palmitoyl derivative) may be used as an antifungal active drug providing further investigation.

Table 7. MIC and MFC values for compounds 7 and 12 against $C$. albicans

\begin{tabular}{ccc}
\hline Compound No. & MIC $(\mathrm{mg} / \mathrm{ml})$ & MFC $(\mathrm{mg} / \mathrm{ml})$ \\
\cline { 2 - 3 } & Candida albicans & Candida albicans \\
\hline 7 & 0.63 & 1.25 \\
12 & 1.25 & 2.50 \\
\hline
\end{tabular}

According to the MIC and MFC data above, both compounds had similar levels of potency.

In a word this series of test compounds were found to show very good antibacterial and antifungal activity, particularly the presence of different acyl groups e.g. palmitoyl, dichloroacetyl, etc. groups improved the antibacterial and antifungal activity by a very good margin which was in accordance with our previous work (Kawsar et al. 2015a). We believe that a similar hydrophobic interaction might occur between the acyl chains of thymidine accumulated in the lipid-like nature of the bacteria membranes. As a consequence of their hydrophobic interaction, bacteria lose their membrane permeability, ultimately causing the death of the bacteria (Hunt 1975, Kim et al. 2007, Judge et al. 2013).

\section{Effect of test chemicals on EAC cells}

MTT assay (Fig. 3) was used to investigate the effect of compound (4) and (7) in vitro on EAC cells. Death of EAC cells induced by compound (4) and (7) occurred in a dose-dependent manner (Fig. 3). At $200 \mu \mathrm{g} / \mathrm{ml}$, the inhibitory effect of compounds (4) and (7) were $13.04 \%$ and $14.27 \%$, respectively. When the concentration decreased gradually, the inhibitory effect also reduced and finally reached to $1.34 \%$ and $2.02 \%$ at $6.25 \mu \mathrm{g} / \mathrm{ml}$ 
of compound (4) and (7), respectively. The $\mathrm{IC}_{50}$ values for compound (4) and (7) were determined to be $920.88 \mu \mathrm{g} / \mathrm{ml}$ and $792.90 \mu \mathrm{g} / \mathrm{ml}$, respectively.

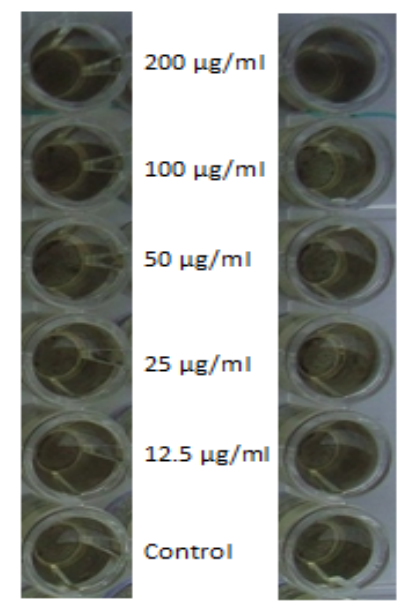

Fig. 3. Anticancer screening of compounds 4 and 7 .

\section{Conclusion}

The results of the present investigation showed that some of the newly synthesized acylated derivatives of thymidine may possess a wide range of antimicrobial and anticancer activities. So the acylated derivatives of thymidine may be considered as a potential source for developing new and better antimicrobial agents. Further, it is also expected that this piece of work employing thymidine derivatives as test compounds will help further work to the development of pesticides and medicine for the treatment of plant or mankind disease. Besides, the antiviral and antidiabetic activities of the thymidine derivatives thereof are currently under investigation and will be published in a forthcoming paper.

\section{Acknowledgments}

The authors are very much thankful to the Research and Publication Cell, University of Chittagong, Bangladesh for providing financial support to carry out this research project.

\section{References}

Ahmed FRS, Amin R, Hasan I, Asaduzzaman AKM and Kabir SR (2017). Antitumor properties of a methyl- $\beta$-Dgalactopyranoside specific lectin from Kaempferia rotunda against Ehrlich ascites carcinoma cells. International Journal of Biological Macromolecules, 102: 952-959.

Amsterdam D (2005). Susceptibility testing of antimicrobials in liquid media, In: Lorian V (ed.), Antibiotics in laboratory medicine, $5^{\text {th }}$ ed. Williams L. \& Wilkins, Philadelphia, PA, pp. 61.

Arifuzzaman M, Mirajul MI, Monjur MR, Atiar MR and Kawsar SMA (2018). An efficient approach to the synthesis of thymidine derivatives containing various acyl groups: characterization and antibacterial activities. ACTA Pharmaceutica Sciencia, 56: 7-22.

Bauer AW, Kirby WMM, Sherris JC and Turck M (1966). Antibiotic susceptibility testing by a standardized single disc method. American Journal of Clinical Pathology, 45: 439-476. 
Clercq ED (2010). Highlights in the discovery of antiviral drugs: A Personal Retrospective. Journal of Medicinal Chemistry, 53: 1438-1450.

Clercq ED (2011). A 40-year journey in search of selective antiviral chemotherapy. Annual Review of Pharmacology and Toxicology, 51: 1-24.

Ghorab MM, Ismail ZHS, Gaward MA and Aziem AA (2004). Antimicrobial activity of amino acid, imidazole and sulfonamide derivativesof pyrazolo[3,4-d]pyrimidine. Heteroatom Chemistry, 15: 57-62.

Grover RK and Moore JD (1962). Toximetric studies of fungicides against the brown rot organisms Sclerotinia flucticola and S. laxa. Phytopathology, 52: 876-880.

Gupta RS, Paul AK, Gupta P, Kachroo L and Bani S (1997). Synthesis and biological activities of some 2-substituted phenyl-3-(3-alkyl/aryl-5,6-dihydro-s-triazolo[3,4-b] [1, 3, 4] thiazol-6-yl) indoles. Indian Journal of Chemistry, 36: 707-710.

Hui XP, Chu CH and Zhang ZY (2002). Synthesis and antibacterial activities of 1, 3, 4-triazole derivatives containing 5methylisoxazole moiety. Indian Journal of Chemistry, 41: 2176-2179.

Hunt WA (1975). The Effects of aliphatic alcohols on the biophysical and biochemical correlates of membrane function. Advances in Experimental Medicine and Biology, 56: 195-210.

Johannes Z, Silke B, Hanns A and Thomas AW (2010). Synergistic antimicrobial activities of folic acid antagonists and nucleoside analogs. Antimicrobial Agents and Chemotherapy, 54: 1226-1231.

Jordheim LP, Durantel D, Zoulim F and Dumontet C (2013). Advances in the development of nucleoside and nucleotide analogues for cancer and viral diseases. Nature Reviews Drug Discovery, 12: 447-464.

Judge V, Narasimhan B, Ahuja M, Sriram D, Yogeeswari P, Clercq ED, Pannecouque C and Balzarini J (2013). Synthesis, antimycobacterial, antiviral, antimicrobial activity and QSAR studies of N2-acyl isonicotinic acid hydrazide derivatives. Medicinal Chemistry 9: 53-76.

Kabir AKMS, Dutta P and Anwar MN (2003). Synthesis of some derivatives of D-mannose for biological studies. Bulletin of Pure and Applied Sciences, 22: 119-127.

Kabir AKMS, Kawsar SMA, Bhuiyan MMR, Islam MR and Rahman MS (2004). Biological evaluation of some mannopyranoside derivatives. Bulletin of Pure and Applied Sciences, 23: 83-91.

Kawsar SMA, Faruk MO, Rahman MS, Fujii Y and Ozeki Y (2014). Regioselective synthesis, characterization and antimicrobial activities of some new monosaccharide derivatives. Scientia Pharmaceutica, 82: 1-20.

Kawsar SMA, Hamida AA, Sheikh AU, Hossain MK, Shagir AC, Sanaullah AFM, Manchur MA, Imtiaj H, Ogawa Y, Fujii Y, Koide $Y$ and Ozeki $Y$ (2015a). Chemically modified uridine molecules incorporating acyl residues to enhance antibacterial and cytotoxic activities. International Journal of Organic Chemistry, 5: 232-245.

Kawsar SMA, Khaleda M, Asma R, Manchur MA, Koide Y and Ozeki Y (2015b). Infrared, ${ }^{1} \mathrm{H}-\mathrm{NMR}$ spectral studies of some methyl 6-O-myristoyl-a-D-glucopyranoside derivatives: assessment of antimicrobial effects. International Letters of Chemistry, Physics and Astronomy, 58: 122-136.

Kawsar SMA, Mariam I, Sanjida J, Mohammad AM, Imtiaj H and Sultana R (2018). Evaluation of the antimicrobial activity and cytotoxic effect of some uridine derivatives. International Journal of Biosciences, 12: 211-219.

Kawsar SMA, Nishat SSBS, Manchur MA and Ozeki Y (2016). Benzenesulfonylation of methyl a-D-glucopyranoside: synthesis, characterization and antibacterial screening. International Letters of Chemistry. Physics and Astronomy, 64: 95-105.

Kim YM, Farrah S and Baney RH (2007). Structure-antimicrobial activity relationship for silanols, a new class of disinfectants, compared with alcohols and phenols. International Journal of Antimicrobial Agents, 29: 217-222. 
Kimura K and Bugg TDH (2003). Recent advances in antimicrobial nucleoside antibiotics targeting cell wall biosynthesis. Natural Products Reports, 20: 252-273.

Najera I (2013). Resistance to HCV nucleoside analogue inhibitors of hepatitis C virus RNA-dependent RNA polymerase. Current Opinion in Virology, 3: 508-513.

Parang K, Wiebe LI and Knaus EE (1997). Syntheses and biological evaluation of 5'-O-myristoyl derivatives of thymidine against human immunodeficiency virus. Antiviral Chemistry and Chemotherapy, 8: 417-427.

Patel KD, Mistry BD and Desai KR (2002). Synthesis and antimicrobial activity of 1, 2, 4-triazoles. Journal of Indian Chemical Society, 79: 964-965.

Ri M, Tashiro E, Oikawa D, Shinjo S, Tokuda M, Yokouchi Y, Narita T, Masaki A, Ito A, Ding J, Kusumoto S, Ishida T, Komatsu H, Shiotsu Y, Ueda R, Iwawaki T, Imoto M and lida S (2012). Identification of Toyocamycin, an agent cytotoxic for multiple myeloma cells, as a potent inhibitor of ER stress-induced XBP1 mRNA splicing. Blood Cancer Journal, 2: e79.

Sumi RD, Sanjida J, Mahfuz R, Mohammad AM, Yuki F, Robert AK, Ozeki Y and Kawsar SMA (2019). Microbial efficacy and two step synthesis of uridine derivatives with spectral characterization. ACTA Pharma. Sciencia, 57: 47-68.

Yarchoan R, Mitsuya H and Broder S (1988). AIDS Therapies. Scientific American, 259: 110-119.

(Manuscript received on 03 April 2020; revised on 24 June 2020) 